\title{
The incorporation of virtual ergonomics to improve the occupational safety condition in a factory
}

\author{
Karin Kandananond* \\ Valaya Alongkorn Rajabhat University, Prathumthani, Thailand
}

Received: 30 June 2018 / Accepted: 3 October 2018

\begin{abstract}
Proper manual material handling (MMH) is the important step leading to the occupational safety of the workers on the shop floor as well as the productivity improvement of the manufacturing process. The objectives of this study are the application of different risk assessment methods, the redesign of the workstation to reduce the occupational risk and the utilization of software package to validate the proposed interventions. As a result, an assembly line of a product is selected as the case study to validate the proposed agenda. Afterwards, four lifting assessment methods, i.e. NIOSH lift equation, Snook Psychophysical Table, OSU Lift guidelines and $\mathrm{ACGIH} / \mathrm{TLV}$, are used to assess the hazard risk in the assembly line. After these methods are performed, the results are introduced to recommend the newly designed working conditions, i.e. postures, movements and the barriers. To validate the improved design, new configurations are simulated by the virtual ergonomic program and the ergonomic analysis is performed. The important results, e.g. low back compression and percent of population capable, are calculated by the software to determine the appropriate values which are used as the guidelines for a safe working condition. Moreover, the manufacturing process is also simulated to improve that the ergonomic redesign of the shop floor environment and another consequence of the implementation leads to the significant increase of the productivity.
\end{abstract}

Keywords: assembly line / lifting assessment / manual material handling / productivity / virtual ergonomics

\section{Introduction}

Manual material handling (MMH) activities include lifting, lowering, pushing, pulling and carrying. These are the activities inducing the physical hazards among factory workers in the industries routinely exposed to. Moreover, most of them have developed a serious work-related musculoskeletal disorder. Therefore, if the root causes of these hazards are properly identified and efficiently controlled, it will help to minimize and prevent the work-related musculoskeletal injuries. In this research, the different approaches have been developed to assess the injuries and determine the acceptable weight of the MMH activities. These approaches include National Institute for Occupational Safety and Health (NIOSH) lift equation, Snook's Psychophysical Table, Ohio State University (OSU) lifting guidelines and American Conference of Governmental Industrial Hygienists/ Threshold Limit Values (ACGIH/TLV). NIOSH lift equation is a method utilized in order to assess the risk of material handling, especially, lifting. It needs some data (vertical, horizontal distance, angle, frequency and weight of

\footnotetext{
* Corresponding author: karin@vru.ac.th
}

the load) and provides the lifting index for any tasks. On the other hand, Snook's Psychophysical Table, also known as Snook's Table, is based on the research of Stover Snook and Vincent Ciriello at the Liberty Mutual Research Institute for Safety. Snook's Table gives the maximum lifting weight due to the gender, population percentile and horizontal distance. Ohio State University (OSU) lifting guidelines were developed by the Ohio State University's Biodynamics Laboratory to provide guidelines regarding the design of lifting task. Another method is ACGIH/TLV, which is a list of recommended occupational exposure limits by American Conference of Governmental Industrial Hygienists. For the benchmarking, OSU lifting guidelines and ACGIH/TLV provide the acceptable weight to lift when some characteristics of lifting tasks such as the origin height, duration, frequency and reach are known.

Since there are a number of methods used to assess the occupational risk due to the lifting and each method is different, it is difficult to point out the best method to identify the accurate and precise risk of lifting tasks. Moreover, another dilemma is the validation of the intervention measures that are suggested to be implemented in the shop floor because, most of the time, it is difficult to conduct the actual intervention in the workplace. 
As a result, the objectives of this research have three folds. The first is to carry out the study of the integrated utilization of different assessment methods to achieve the best result. The latter is to assess the effectiveness of the intervention measures. The second objective is to utilize the ergonomic simulation package to perform the assessment of proposed interventions. The last objective is the determination of the relationship between the productivity improvement and the intervention.

\section{Literature review}

The question regarding the most appropriate risk assessment method and how to integrate these methods together are crucial and need the clear answer. There are few studies conducted to compare each assessment method. Russell, Winnemuller, Camp and Johhson [1] compared the assessment results from NIOSH, ACGIH/TLV, Snook, 3D Static Strength Prediction Program (3DSSPS) and Washington State Department of Labor and Industries (WA L\&I). The task performed is the lifting of milk cases and the results from NIOSH, ACGIH/TLV and Snook are similar due to different patterns of exposure and lifting height.

The effect of repetitive box lifting in the severe environment is studied by Maresh et al. [2]. The results point out that the performance of lifters is greatly enhanced by the frequency of repetition and the temperature. Moreover, the productivity is also influenced by both of these factors.

Kazmierczak et al. [3] have investigated the newly designed configurations of the car disassembly process. The system is redesigned on the basis of ergonomics guidelines and the relationship between the ergonomics and the system performance is also studied. The study shows that the cycle time has a smaller variation and a higher output in the number of cars per week after the ergonomics intervention is implemented. Moreover, Karakolis et al. [4] studied the relationship between the musculoskeletal discomfort and the productivity in the sit-stand office work. The results illustrate that discomfort has a significant effect on the productivity. A study conducted in the automobile industry by Zare et al. [5] points out that the incorporation of proactive ergonomics, e.g. physical and organizational ergonomics and psychosocial factors into the perception culture of an organization, has the capability to reduce defects and improve quality in the production process. Botti et al. [6] signify that ergonomics in the workplace is an important parameter of the process design, as well as other lean manufacturing parameters, e.g. work in progress, takt time and cycle time.

Kujawinska et al. [7] show that the implementation of ergonomics intervention does not only have an impact on the productivity but also have the significant contribution on the sustainable production, i.e. creating the awareness among the employees that the organization recognizes them as the most valuable resource.

Regazzoni and Rizzi [8] apply the virtual ergonomic to simulate the human model in order to evaluate reachability, visibility, postures, fatigue and stress in the workplace. This is the key factor which leads to the improvement of the maintainability of the organization. The virtual ergonomics is used as a tool by Marzano et al. [9] to simulate a manufacturing process in which the digital human models are created. As a result, the simulation study has suggested new solutions leading to the efficient assembly processes in the railway industry. Sanjog et al. [10] have studied the effectiveness of the utilization of the virtual ergonomic or Digital Human Modeling Software (DHMS) as a tool to create the awareness among small and medium enterprise owners regarding the evaluation and the improvement of the existing workplace.

Backstrand et al. [11] have conducted a study to show that the virtual ergonomic is a powerful tool to support the design of an ergonomic workplace since it has the potential to assess the early stage of the ergonomic conditions in the virtual environment. Colombo et al. [12] used the biomechanical simulation package to validate the result from the computer-designed device in the refrigerator assembly.

\section{Scenario and research procedures}

In this study, the selected scenario to study was an assembly line in a factory. The manufacturing process is a flow system with multi-workstations which are carried out by four workers along the assembly line as shown in the spaghetti diagram (Fig. 1). Before the job is carried out at the first workstation, the required materials are delivered from the factory warehouse (Fig. 2). The materials are packed in the box and routed to the workstation.

According to the working scenarios, the first worker at the incoming workstation is required to lift a box of material whose weight is $20 \mathrm{lbs}$ as shown in Figure 2. Boxes are also lifted from the ground position to the table to start the assembly process. However, since there are medical reports from the safety officer regarding the hazardous condition of this process, the intervention might be required to reduce the amount of injuries.

As a result, the first step is to perform the risk assessment, which is conducted through four different methods: NIOSH lift equation, Snook's Psychophysical Tables, OSU lift guidelines and ACGIH/TLV. Afterward, the proper intervention recommended by the assessment is used as the inputs for the virtual environment software. After the simulation, the assessment of the newly designed process will be performed to analyze the risk of the new working condition. Moreover, the improved manufacturing process will be simulated to determine the relationship between the productivity and the ergonomic intervention.

\section{Risk assessment}

The health hazard assessment is conducted by considering four methods, NIOSH lift equation, Snook's Psychophysical Tables, OSU lift guidelines and ACGIH/TLV, as follows:

\subsection{Niosh lift equation}

The analysis by using NIOSH lift equation is divided into two parts, from the floor to the table and from the box to the table, according to the lifting condition. The lifting index (LI) and recommended weight limit (RWL) of these two lifting 


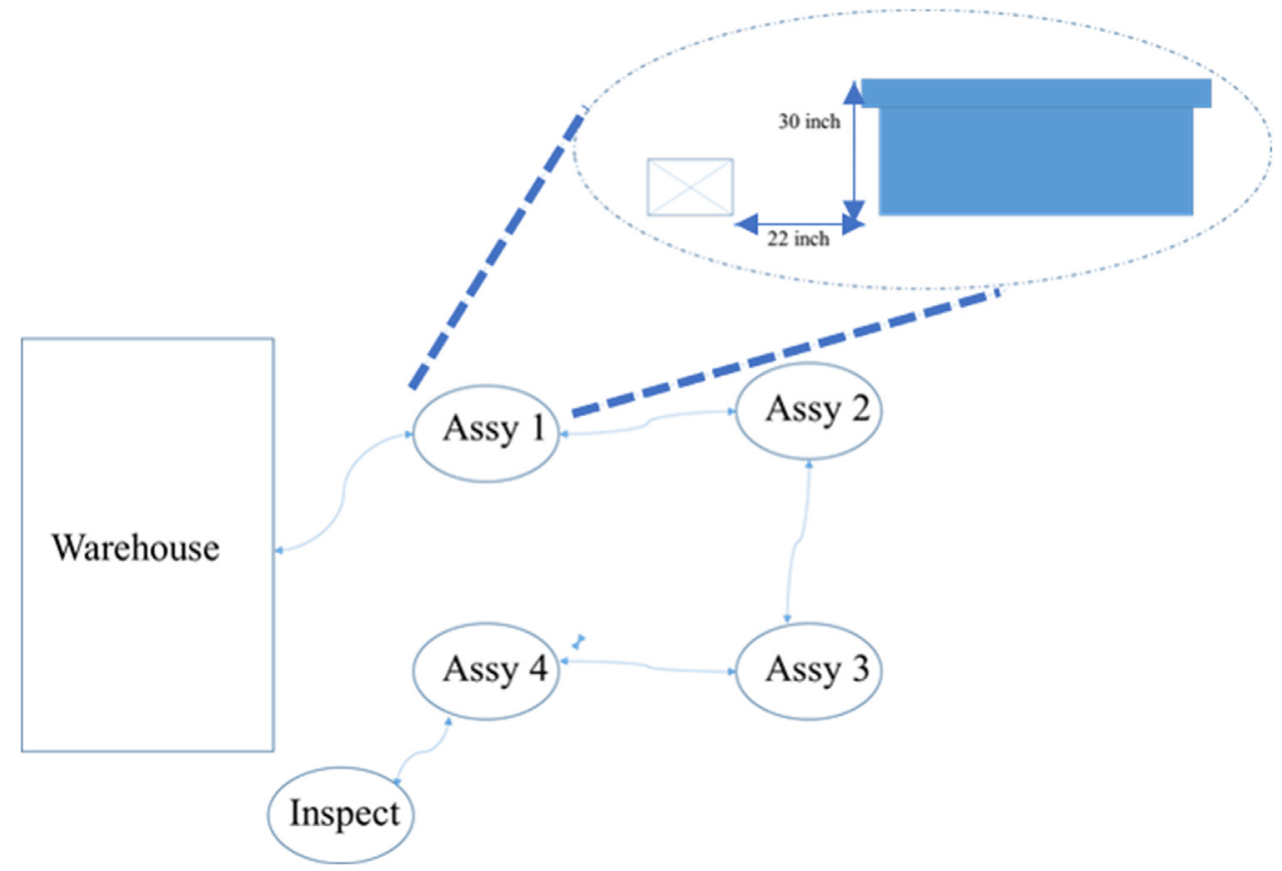

Fig. 1. Assembly process and the focused workstation.

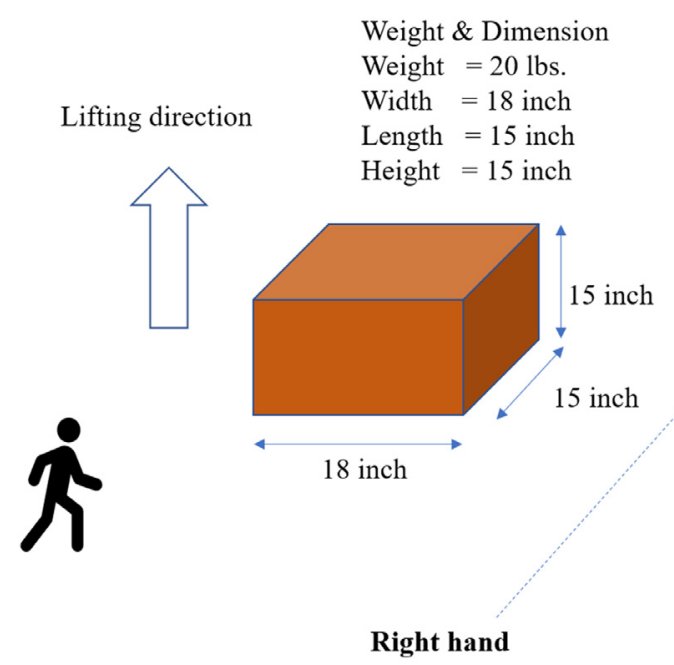

Fig. 2. Material boxes to be carried.

conditions are shown in Figures 3 and 4 consecutively. The NIOSH lift equation analysis when the box is lifted from the floor to the table is performed in Figure 3. The results illustrate that, at the origin, the RWL is $9.495 \mathrm{lbs}$, while the LI is 2.106. On the other hand, the RWL at the destination is $13.023 \mathrm{lbs}$ and the $\mathrm{LI}$ is 1.5357 .

The NIOSH lift equation analysis from the box to the table is shown in Figure 4. At the origin, the RWL is $12.545 \mathrm{lbs}$, while the LI is 1.594. The RWL at the destination is $15.439 \mathrm{lbs}$ and the LI is 1.295.

\subsection{Snook's psychophysical tables}

Snook's Psychophysical Tables or the Liberty Mutual MMH Tables were developed by Dr. Stover Snook and
Dr. Vincent Ciriello at the Liberty Mutual Research Institute for Safety with the purpose of analyzing and evaluating lifting, lowering, pulling, pushing and carrying tasks. It is interesting to notice that the tables have the capability to determine the percentage of male or female workers who can perform certain jobs. Therefore, the analysis is categorized into two cases according to the gender.

(1) Male

Lifting from the floor to the table:

Box width $=18^{\prime \prime} \times 2.54=45.72 \mathrm{~cm} \sim 46-49 \mathrm{~cm}$, vertical distance of lower $=(30-3.5)^{\prime \prime} \times 2.54=67.31 \mathrm{~cm}$ $\sim 76 \mathrm{~cm}$, percentile $=90 \%$. Due to Snook Table in Figure 5, the maximum acceptable weight is $13 \mathrm{~kg}$.

Lifting from the knee level to the table:

Box width $=18^{\prime \prime} \times 2.54=45.72 \mathrm{~cm} \sim 46-49 \mathrm{~cm}$, vertical distance of lower $=(30-22)^{\prime \prime} \times 2.54=23.32 \mathrm{~cm} \sim 25 \mathrm{~cm}$, percentile $=90 \%$. The maximum acceptable weight is $16 \mathrm{~kg}$ (Fig. 5).

(2) Female

Lifting from the floor to the table:

Box width $=18^{\prime \prime} \times 2.54=45.72 \mathrm{~cm} \sim 46-49 \mathrm{~cm}$, vertical distance of lower $=(30-3.5)^{\prime \prime} \times 2.54=67.31 \mathrm{~cm} \sim 76 \mathrm{~cm}$, percentile $=90 \%$. The maximum acceptable weight is $8 \mathrm{~kg}$ (Fig. 6).

Lifting from the knee level to the table:

Box width $=18^{\prime \prime} \times 2.54=45.72 \mathrm{~cm} \sim 46-49 \mathrm{~cm}$, vertical distance of lower $=(30-22)^{\prime \prime} \times 2.54=20.32 \mathrm{~cm} \sim 25 \mathrm{~cm}$, percentile $=90 \%$. The maximum acceptable weight is $9 \mathrm{~kg}$ (Fig. 6).

\subsection{OSU lift guidelines}

For OSU lift guidelines, the analysis mainly depends on the vertical lift origin (floor level or knee level), the health 


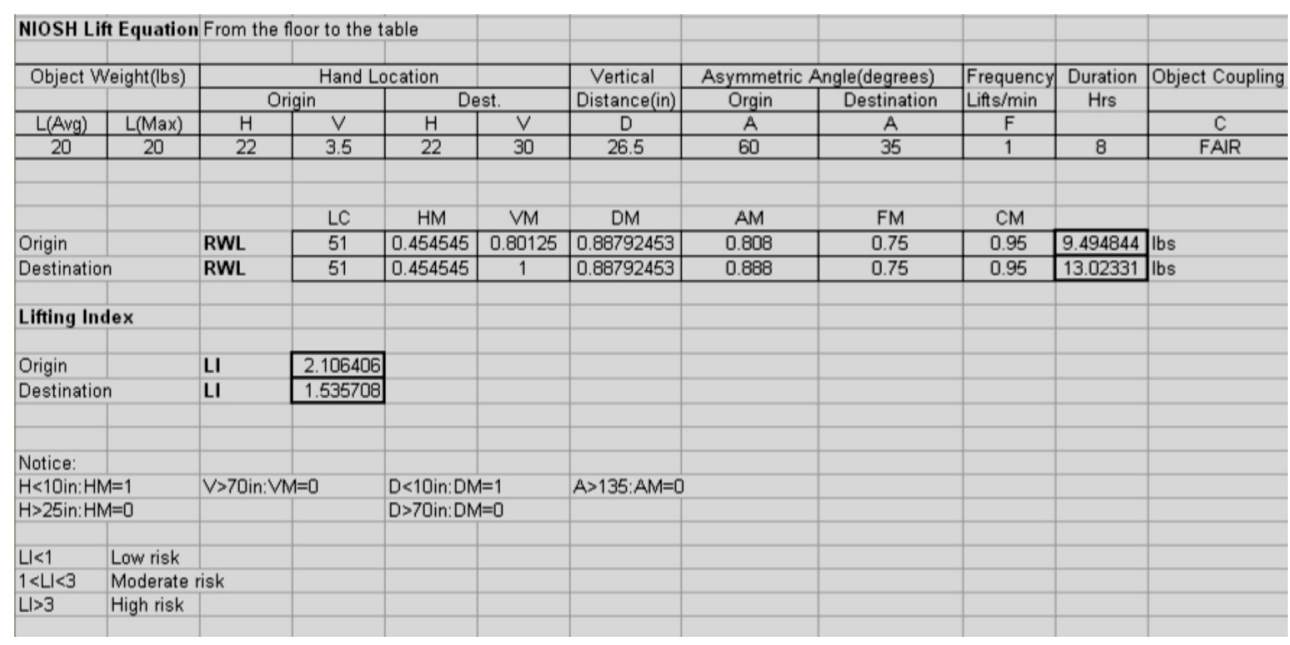

Fig. 3. NIOSH lift equation analysis results (from the floor to table).

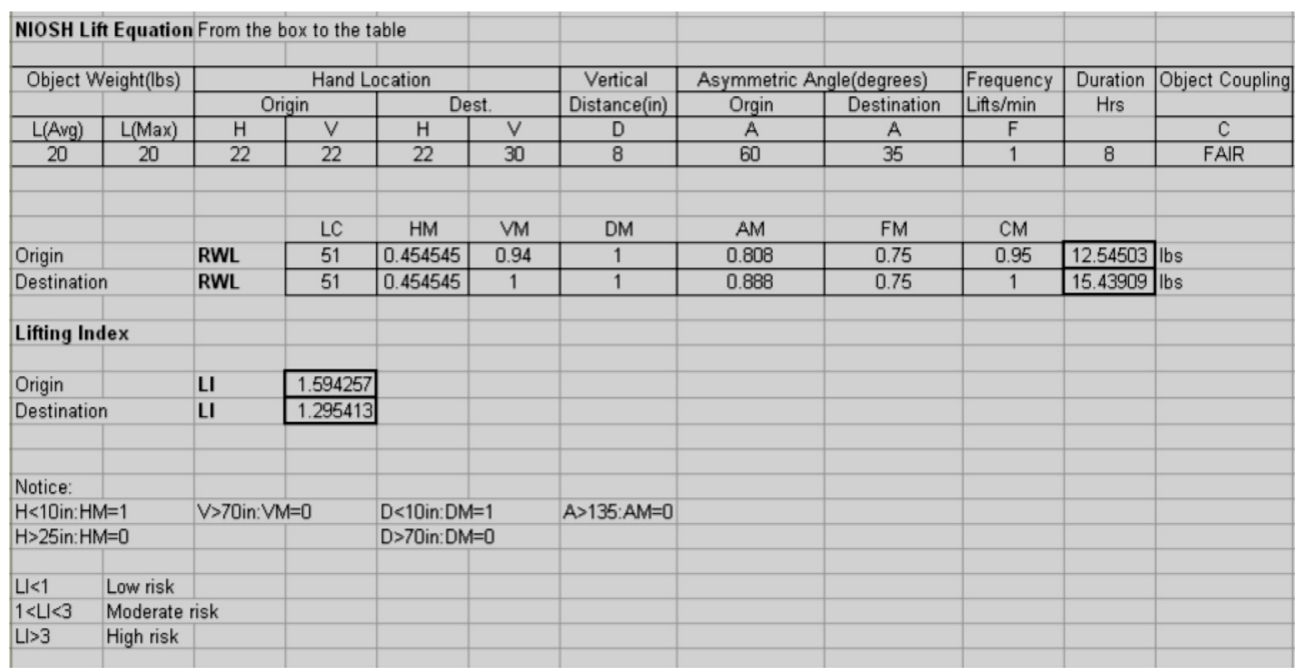

Fig. 4. NIOSH lift equation analysis results (from the box to table).

history and torso twisting to determine the risk and maximum safe load.

(1) From the floor

Vertical lift origin: Floor level

Reach: 22" (between $12^{\prime \prime}$ and $24^{\prime \prime}$ )

Health history: Healthy

Torso twisting: $60^{\circ}$ (between $60^{\circ}$ and $90^{\circ}$ )

Therefore, there is high risk and the maximum safe load is 0 pounds.

(2) From the floor

Vertical lift origin: Knee level

Reach: $22^{\prime \prime}$ (between $12^{\prime \prime}$ and $24^{\prime \prime}$ )

Health history: Healthy

Torso twisting: $60^{\circ}$ (between $60^{\circ}$ and $90^{\circ}$ )

Therefore, there is moderate risk for weight less than $20 \mathrm{lbs}$ and the high risk for the weight more than $20 \mathrm{lbs}$.

\subsection{ACGIH/TLV}

To comply with the lifting condition, the assessment by ACGIH/TLV is separated into two cases:

(1) Origin at floor to mid-shin

Lifting zones: Floor to mid-shin

Reach: Middle lift, $22^{\prime \prime} \times 2.54=55.88 \mathrm{~cm} \sim 30-60 \mathrm{~cm}$

Frequency: $60 \mathrm{lifts} / \mathrm{min}$ (>30 lifts $/ \mathrm{min}$ )

Duration: $8 \mathrm{~h}$ a day $(>2 \mathrm{~h} /$ day $)$

Asymmetry: $60^{\circ}$

The result from ACGIH TLV table is "No safe limit known."

(2) Origin at mid-shin to knuckle

Lifting zones: Mid-shin to knuckle

Reach: Middle lift, $22^{\prime \prime} \times 2.54=55.88 \mathrm{~cm} \sim 30-60 \mathrm{~cm}$

Frequency: 60 lifts/ $\min (>30 \mathrm{lifts} / \mathrm{min})$ 


\begin{tabular}{|c|c|c|c|c|c|c|c|c|c|c|}
\hline & & & \multicolumn{8}{|c|}{$\begin{array}{c}\text { Floor level to knuckle height } \\
\text { One lift every }\end{array}$} \\
\hline & & & 5 & 9 & 14 & 1 & 2 & 5 & 30 & 8 \\
\hline & & & \multicolumn{3}{|c|}{8} & \multicolumn{3}{|c|}{$\min$} & \multicolumn{2}{|c|}{$\mathrm{h}$} \\
\hline & & 90 & 6 & 7 & 9 & 11 & 13 & 14 & 14 & 17 \\
\hline & & 75 & 9 & 11 & 13 & 16 & 19 & 20 & 21 & 24 \\
\hline & 76 & 50 & 12 & 15 & 17 & 22 & 25 & 27 & 28 & 32 \\
\hline & & 25 & 15 & 18 & 21 & 28 & 31 & 34 & 35 & 41 \\
\hline & & 10 & 18 & 22 & 25 & 33 & 37 & 40 & 41 & 48 \\
\hline \multirow{24}{*}{75} & \multirow{5}{*}{51} & 90 & 6 & 8 & 9 & 12 & 13 & 15 & 15 & 17 \\
\hline & & 75 & 9 & 11 & 13 & 17 & 19 & 21 & 22 & 25 \\
\hline & & 50 & 13 & 15 & 18 & 23 & 26 & 28 & 29 & 34 \\
\hline & & 25 & 16 & 19 & 22 & 29 & 33 & 35 & 36 & 42 \\
\hline & & 10 & 19 & 22 & 26 & 34 & 38 & 42 & 43 & 50 \\
\hline & \multirow{5}{*}{25} & 90 & 8 & 9 & 11 & 13 & 15 & 16 & 17 & 20 \\
\hline & & 75 & 11 & 13 & 15 & 19 & 22 & 24 & 24 & 28 \\
\hline & & 50 & 15 & 18 & 21 & 26 & 29 & 32 & 33 & 38 \\
\hline & & 25 & 18 & 22 & 26 & 33 & 37 & 40 & 41 & 48 \\
\hline & & 10 & 22 & 26 & 31 & 38 & 44 & 47 & 49 & 57 \\
\hline & & & 7 & 8 & 10 & 13 & 15 & 16 & 17 & 20 \\
\hline & & 75 & 10 & 12 & 14 & 19 & 22 & 24 & 24 & 28 \\
\hline & & 50 & 14 & 16 & 19 & 26 & 29 & 32 & 33 & 38 \\
\hline & & 25 & 17 & 20 & 24 & 33 & 37 & 40 & 41 & 48 \\
\hline & & 10 & 20 & 24 & 28 & 38 & 43 & 47 & 48 & 57 \\
\hline & \multirow{5}{*}{51} & 90 & 7 & 9 & 10 & 14 & 16 & 17 & 18 & 20 \\
\hline & & 75 & 10 & 13 & 15 & 20 & 23 & 25 & 25 & 30 \\
\hline & & 50 & 14 & 17 & 20 & 27 & 30 & 33 & 34 & 40 \\
\hline & & 25 & 18 & 21 & 25 & 34 & 38 & 42 & 43 & 50 \\
\hline & & 10 & 21 & 25 & 29 & 40 & 45 & 49 & 50 & 59 \\
\hline & & (90) & 8 & 10 & 12 & 16 & 18 & 19 & 20 & 23 \\
\hline & & 75 & 12 & 15 & 17 & 23 & 26 & 28 & 29 & 33 \\
\hline & & 50 & 16 & 20 & 23 & 30 & 34 & 37 & 38 & 45 \\
\hline & & 25 & 21 & 25 & 29 & 38 & 43 & 47 & 48 & 56 \\
\hline
\end{tabular}

Fig. 5. Snook's Table showing maximum lifting weight for male.

Duration: $8 \mathrm{~h}$ a day $(>2 \mathrm{~h} /$ day $)$

Asymmetry: $60^{\circ}$

The result from ACGIH TLV table is $14 \mathrm{~kg}$.

\section{Risk analysis results}

The NIOSH lift equation shows that the value of lifting index (LI) is equal to 2.106406 for lifting from the floor to the table, while the LI of lifting from the box to the table is 1.594257. The difference in this LI value results implies that the lifting from the low origin increases the risk of injury than from the low origin. If Snook's Table is deployed to achieve the acceptable weight of lifting, the result will be categorized as groups of male and female. For male, the acceptable weight to lift load from the table is $13 \mathrm{~kg}$, which is lower than lifting from the box $(16 \mathrm{~kg})$. For female, the result is similar to the case of male (from the table: $8 \mathrm{~kg}$, from the box: $9 \mathrm{~kg}$ ). Additionally, the result from the OSU lifting guidelines and ACGIH/ TLV also confirms that the lifting from the low level, e.g. floor level, generates more risk than lifting from the higher level, e.g. the knee level or mid-shin. In conclusion, the vertical distance of the lifting and the lifting from the low origin is the important factor that causes the injuries. The NIOSH lift equation clearly shows that the values of HM (0.454545), AM (0.808) and FM (0.75) are relatively low when compared with the maximum value (1). It means that these characteristics are the prime factor of the hazard. For HM, this value can be increased by reducing the distance between the load and the body (relocate the position of the loading site of the boxes) or moving the table closer to the body. For AM, this relates to the twisting angle, and it can be increased by reducing the asymmetric angle and again the approach should be the relocation of the loading site of the box, which will decrease the twisting angle. For FM, the job rotation and providing breaks can increase the value of FM. Other approaches to improve the workplace are lowering the height of the table, elevating the level of the loading site. These can result in the increase of the acceptable weight when Snook's Table, OSU lifting guidelines and ACGIH/ TLV are deployed to do the analysis. 


\begin{tabular}{|c|c|c|c|c|c|c|c|c|c|c|}
\hline & & & \multicolumn{8}{|c|}{$\begin{array}{c}\text { Floor level to knuckle height } \\
\text { One lift every }\end{array}$} \\
\hline & & & 5 & 9 & 14 & 1 & 2 & 5 & 30 & 8 \\
\hline & & & \multicolumn{4}{|c|}{$\mathrm{s}$} & \multicolumn{4}{|c|}{$\min$} \\
\hline & 76 & $\begin{array}{l}90 \\
75 \\
50 \\
25 \\
10\end{array}$ & $\begin{array}{c}5 \\
7 \\
8 \\
9 \\
11\end{array}$ & $\begin{array}{c}6 \\
8 \\
10 \\
11 \\
13\end{array}$ & $\begin{array}{l}7 \\
9 \\
10 \\
12 \\
14\end{array}$ & $\begin{array}{l}7 \\
9 \\
11 \\
13 \\
14\end{array}$ & $\begin{array}{l}8 \\
10 \\
12 \\
14 \\
15\end{array}$ & $\begin{array}{l}8 \\
10 \\
12 \\
14 \\
16\end{array}$ & $\begin{array}{c}9 \\
11 \\
13 \\
15 \\
17\end{array}$ & $\begin{array}{l}12 \\
14 \\
17 \\
21 \\
23\end{array}$ \\
\hline \multirow[t]{5}{*}{75} & 51 & $\begin{array}{l}90 \\
75 \\
50 \\
25 \\
10\end{array}$ & $\begin{array}{c}6 \\
7 \\
9 \\
10 \\
11\end{array}$ & $\begin{array}{c}8 \\
9 \\
10 \\
12 \\
14\end{array}$ & $\begin{array}{l}8 \\
9 \\
11 \\
13 \\
15\end{array}$ & $\begin{array}{l}9 \\
10 \\
12 \\
15 \\
17\end{array}$ & $\begin{array}{c}9 \\
11 \\
13 \\
16 \\
18\end{array}$ & $\begin{array}{c}9 \\
11 \\
14 \\
16 \\
18\end{array}$ & $\begin{array}{l}10 \\
13 \\
15 \\
18 \\
20\end{array}$ & $\begin{array}{c}14 \\
17 \\
21 \\
24 \\
27\end{array}$ \\
\hline & 25 & $\begin{array}{l}90 \\
75 \\
50 \\
25 \\
10\end{array}$ & $\begin{array}{c}6 \\
8 \\
10 \\
11 \\
13\end{array}$ & $\begin{array}{c}7 \\
10 \\
12 \\
14 \\
16\end{array}$ & $\begin{array}{l}8 \\
11 \\
13 \\
15 \\
17\end{array}$ & $\begin{array}{c}8 \\
11 \\
13 \\
15 \\
17\end{array}$ & $\begin{array}{c}9 \\
12 \\
14 \\
16 \\
19\end{array}$ & $\begin{array}{l}9 \\
12 \\
14 \\
17 \\
19\end{array}$ & $\begin{array}{c}11 \\
13 \\
16 \\
19 \\
21\end{array}$ & $\begin{array}{c}14 \\
18 \\
21 \\
25 \\
29\end{array}$ \\
\hline & & $\begin{array}{l}50 \\
25 \\
10\end{array}$ & $\begin{array}{c}5 \\
7 \\
8 \\
9 \\
11\end{array}$ & $\begin{array}{c}6 \\
8 \\
10 \\
11 \\
13\end{array}$ & $\begin{array}{c}7 \\
9 \\
10 \\
12 \\
14\end{array}$ & $\begin{array}{l}8 \\
10 \\
12 \\
14 \\
15\end{array}$ & $\begin{array}{c}8 \\
10 \\
12 \\
15 \\
17\end{array}$ & $\begin{array}{l}8 \\
10 \\
13 \\
15 \\
17\end{array}$ & $\begin{array}{c}9 \\
12 \\
14 \\
17 \\
19\end{array}$ & $\begin{array}{c}13 \\
16 \\
19 \\
22 \\
25\end{array}$ \\
\hline & 51 & $\begin{array}{l}90 \\
75 \\
50 \\
25 \\
10\end{array}$ & $\begin{array}{c}6 \\
7 \\
9 \\
10 \\
11\end{array}$ & $\begin{array}{c}7 \\
9 \\
10 \\
12 \\
14\end{array}$ & $\begin{array}{c}8 \\
9 \\
11 \\
13 \\
15\end{array}$ & $\begin{array}{r}9 \\
11 \\
13 \\
16 \\
18\end{array}$ & $\begin{array}{c}10 \\
12 \\
15 \\
17 \\
19\end{array}$ & $\begin{array}{l}10 \\
12 \\
15 \\
17 \\
20\end{array}$ & $\begin{array}{c}11 \\
14 \\
16 \\
19 \\
22\end{array}$ & $\begin{array}{c}15 \\
18 \\
22 \\
26 \\
30\end{array}$ \\
\hline & & $\begin{array}{l}50 \\
25\end{array}$ & $\begin{array}{c}6 \\
8 \\
10 \\
11\end{array}$ & $\begin{array}{c}8 \\
10 \\
12 \\
14\end{array}$ & $\begin{array}{l}8 \\
11 \\
13 \\
15\end{array}$ & $\begin{array}{l}12 \\
14 \\
16\end{array}$ & $\begin{array}{l}10 \\
12 \\
15 \\
18\end{array}$ & $\begin{array}{l}10 \\
13 \\
15 \\
18\end{array}$ & $\begin{array}{l}11 \\
14 \\
17 \\
20\end{array}$ & $\begin{array}{l}15 \\
19 \\
23 \\
27\end{array}$ \\
\hline
\end{tabular}

Fig. 6. Snook's Table showing maximum lifting weight for female.

\section{Virtual ergonomics}

After the risk assessment is done, the new configurations, i.e. new design of the workstation and the box weight, are introduced and used as the basis of the analysis. The virtual ergonomics software, 3D Static Strength Prediction Program (3DSSPP) developed by University of Michigan, is utilized to validate the new design. After the parameters regarding the new configurations of the workplace ergonomics are set as the criterion for running the program, the analysis is performed as shown in Figures 7-13. According to Figures 7 and 8, the male models are rendered when it lifts a box from the ground to the table (Fig. 7) and from the knee level to the table (Fig. 8). The ergonomic parameters regarding the new working condition are shown in Figures 9 and 10. The results from Figure 9 show that the body parts, wrist, elbow, shoulder, torso, hip, knee and ankle, of most people (the lowest percentile is 95) have the capability of performing the lifting from the ground to the table while the compression of the low back (disc L4/L5) is $389.1 \mathrm{lbs}$. The low back compression is in the green zone, which is considered as safe for lifting. The low back pain is 3 times more likely in the yellow zone and 10 times more likely in the red zone. However, when the lifting position is from the knee level to the table, the percent of population capable is reduced (the lowest is at the percentile of 68 at the torso). Moreover, the low back compression is equal to $842.1 \mathrm{lbs}$, which is in the yellow zone (Fig. 10).

The rendered figure of female performing lifting from the ground to the table is illustrated in Figure 11. The percent of population capable and low back compression are shown in Figures 12 and 13. According to Figure 12, the percent of population capable when the box is lifted by female from the ground to the table is at the lowest percentile of 75 (at the shoulder), which is in the yellow zone, while the low back compression is $365.3 \mathrm{lbs}$, which is in the green zone. Therefore, the lifting condition is safe for the workers. 


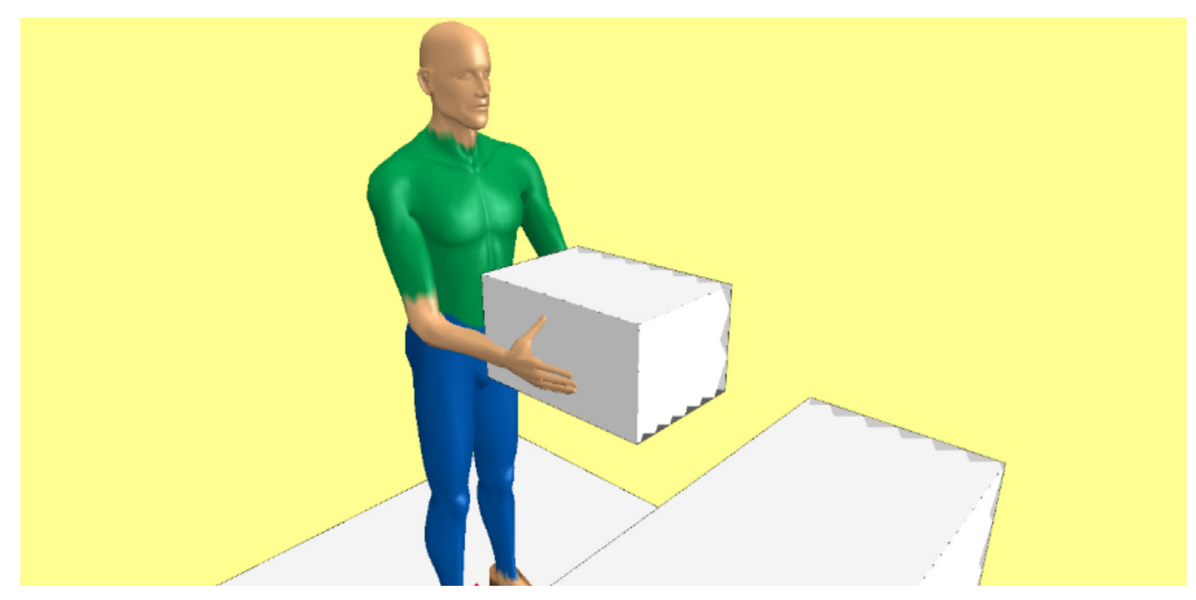

Fig. 7. Rendered figure of male lifting a box from the ground to the table.

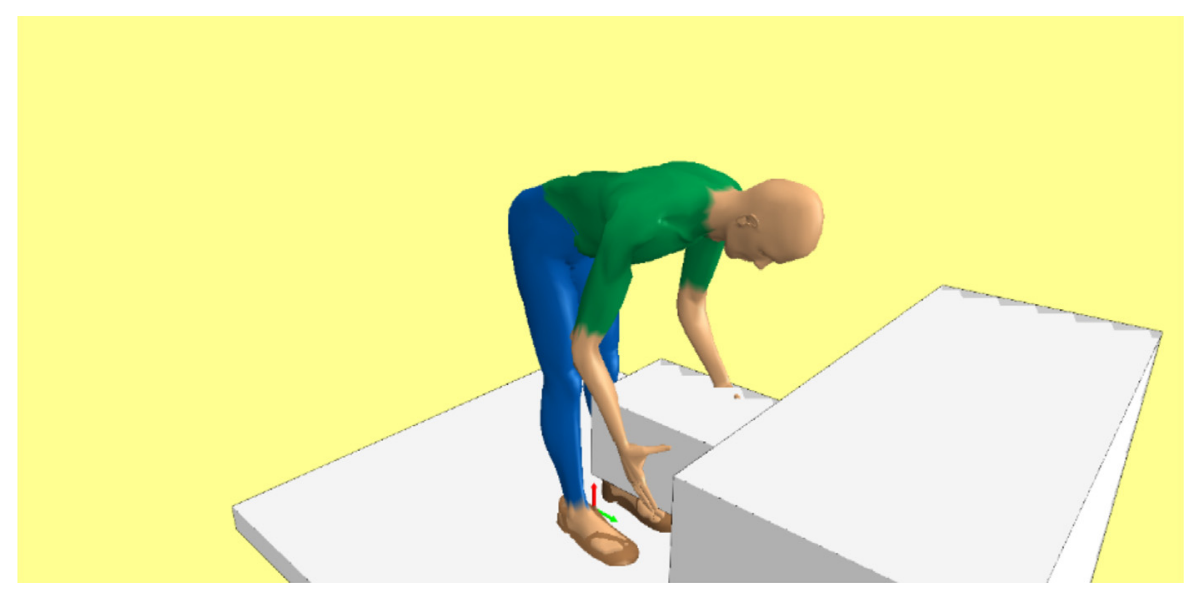

Fig. 8. Rendered figure of male lifting a box from the knee level to the table.

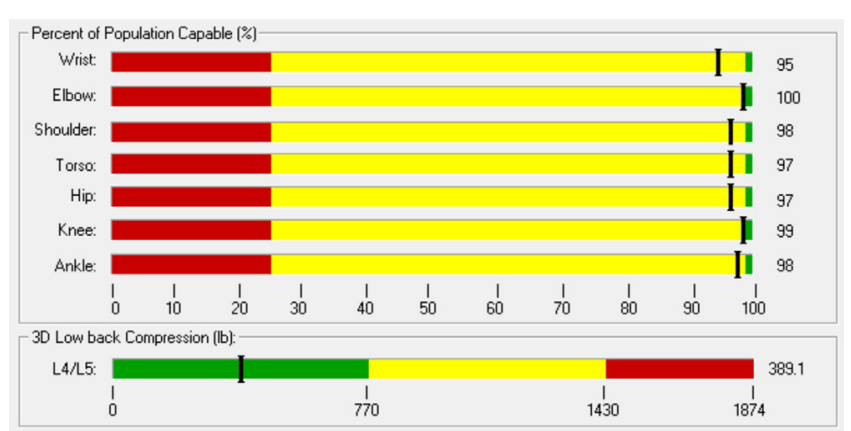

Fig. 9. Parameters of the lifting condition from the ground to the table (male).

On the other hand, when the box is lifted from the knee level to the table, there are three body parts, torso, hip and knee, which percent of population capable is among the lowest (percentile of 54, 40 and 51 consecutively), while the compression of low back is the near the green zone (776.2 lbs), which is on the border line between green and yellow zone. As a result, this lifting position is still regarded as the safe condition for the workers (Fig. 13).

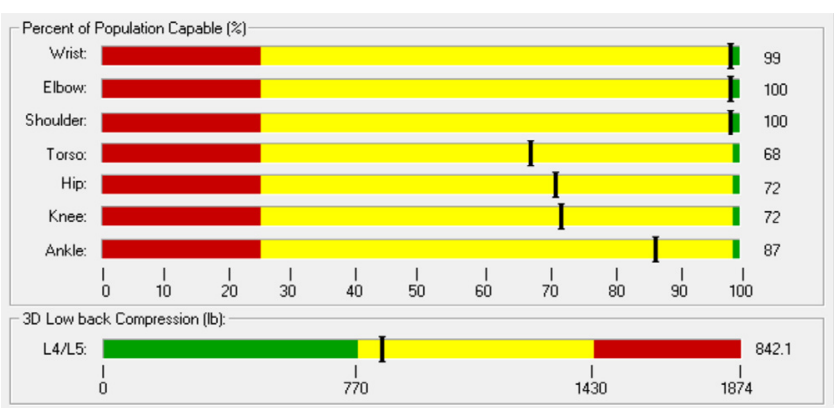

Fig. 10. Parameters of the lifting condition from the knee level to the table (male).

\section{Safety and productivity improvement}

The optimal weight of box, lifting height and the lifting position are recommended by different risk assessment methods. The intervention is implemented at the designated workstation. The injuries statistics are collected and analyzed for a period of 4 months after the intervention. 


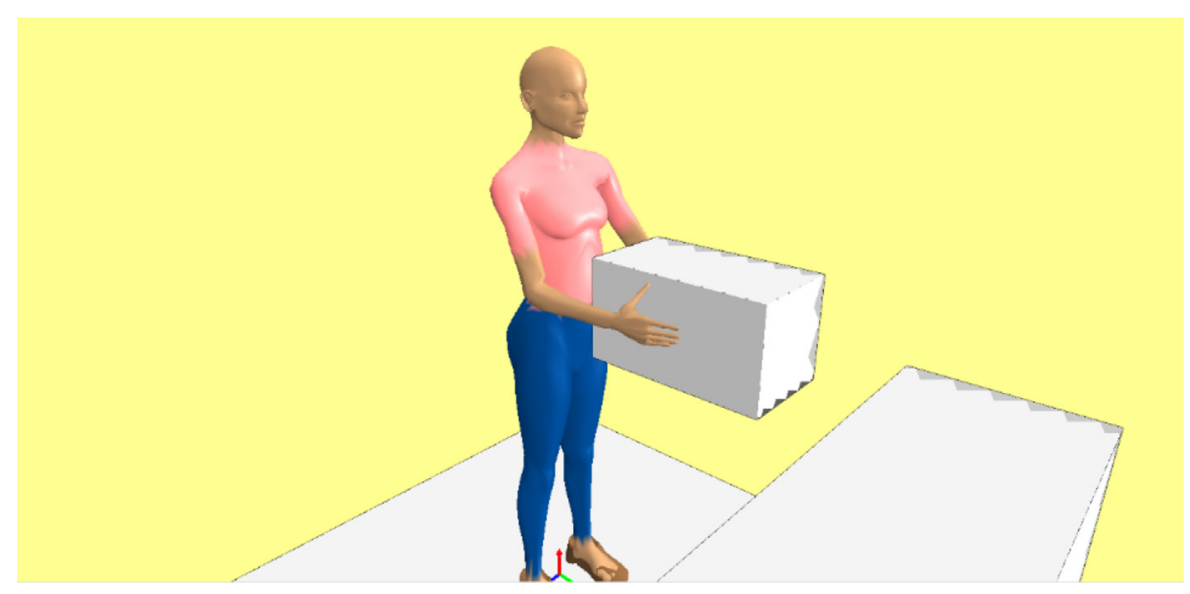

Fig. 11. Rendered figure of female lifting a box from the ground to the table.

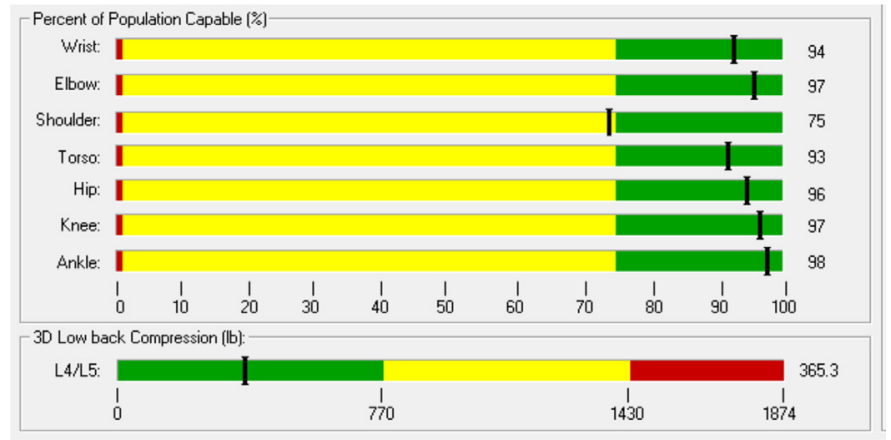

Fig. 12. Parameters of the lifting condition from the ground level to the table (female).

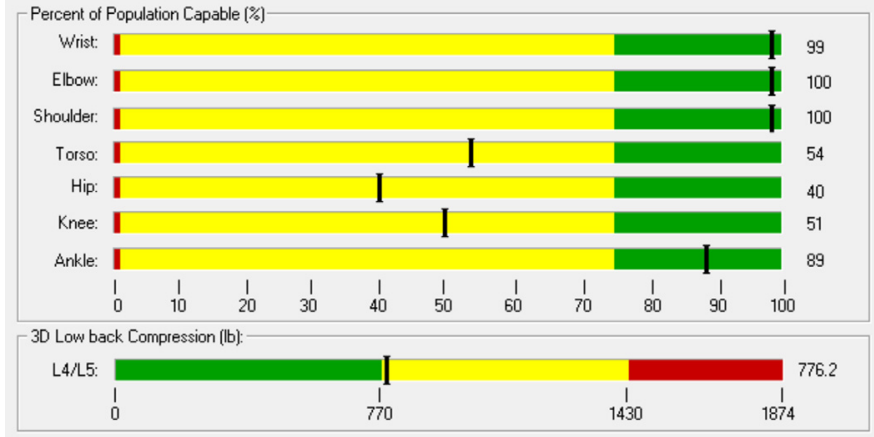

Fig. 13. Parameters of the lifting condition from the knee level to the table (female).

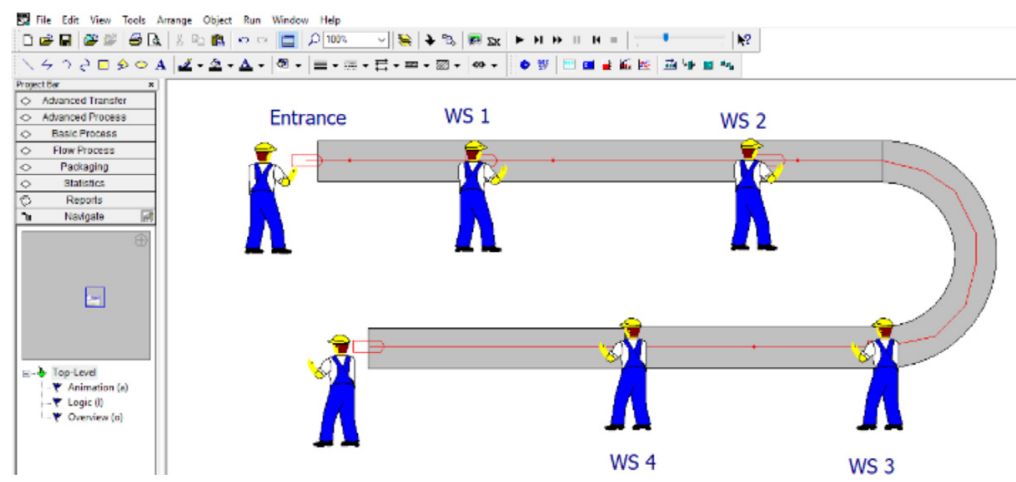

Fig. 14. ARENA simulation of the assembly line.

The results signify that the amount of complains due to back pain and other injuries due to the lifting is significantly reduced by $50 \%$. Similarly, after the results from the virtual ergonomics software are implemented, it significantly increases the number of boxes the worker can lift in a certain period of time. The ARENA package is run and simulated to validate the potential of the ergonomics intervention on the productivity improvement (Fig. 14). The assembly model is modified from the example of assembly line (www.paragon.com.br).

The results from the ARENA based on the $1 \mathrm{~h}$ of production shows that the number of work-in-process (WIP) and the average cycle time are significantly reduced after the intervention. 


\section{Conclusions and discussions}

This study is based on a scenario of the assembly line. Four lifting assessment methods were utilized to assess the risk and hazard while the workers perform the box lifting in the line. The new configurations recommended by the risk assessment are integrated and used as the inputs for the virtual ergonomic software. After each assessment method was implemented, the important finding regarding the risk assessment is that it is better to utilize more than one assessment methods in order to achieve the accurate result. It is also interesting to note that the common results obtained from these methods are the lifting height and the maximum lifting weight. However, NIOSH lift equation also gives the numerical index which is useful to identify the level of risk. Afterward, the software package is utilized to simulate and determine the percent of population capable at different body parts and the low back compression of both male and female population. Therefore, another finding of this study is that virtual ergonomic software is capable of identifying the effectiveness of the implemented intervention. Moreover, the relationship between the ergonomic intervention and the productivity is studied and the results show that the intervention has the significant effect on the improvement of productivity (decreasing number of WIP and cycle time).

\section{References}

1. S.J. Russell, L. Winnemuller, J.E. Camp, P.W. Johnson. Appl. Ergon. 38, 91-97 (2007)

2. C.M. Maresh, B. Sokmen, L.E. Armstrong, J.C. Dias, J.K. Pryor, B.C. Creighton, C.X. Munoz, J.M. Apicellam, D.J. Casa, E.C. Lee, J.M. Anderson, W.J. Kraemer. J. Occup. Environ. Hyg. 11, 460-468 (2014)

3. K. Kazmierczak, W.P. Neumann, J. Winke, Hum. Factor Ergon. Man., 17 (2007)

4. T. Karakolis, J. Barrett, J.P. Callaghan. Ergon., 59 (2016)

5. M. Zare, M. Croq, Hossein-Arabi, Brunet, F.R., Roquelaure, Y., Hum. Factor Ergon. Man., 26, 205-223 (2016)

6. L. Botti, C. Mora, A. Regattieri. Comput. Ind. Eng., 111 (2017)

7. A. Kujawinska, K. Vogt, F. Wachowiak. Environmental Issues in Logistics and Manufacturing, EcoProduction (Springer, Heidelberg, 2015)

8. D. Regazzoni, C. Rizzi. Comput. Aided Des. Appl. 11 (2013)

9. A. Marzano, K. Agyapong-Kodua, S. Ratchev. Procedia CIRP 3 (2012)

10. J. Sanjog, S. Karmakar, T. Patel, Chowdhury. Int. J. Comput. Appl. 54, 18-23 (2012)

11. G. Backstrand, D. Hogberg, L.J. De Vin, K. Case, P. Piamonte. Int. J. Comput. Appl. Tech. 2 (2007)

12. G. Colombo, D. Regazzoni, C. Rizzi. Lect. Notes Comput. Sci. 8026 (2013)

Cite this article as: Karin Kandananond, The incorporation of virtual ergonomics to improve the occupational safety condition in a factory, Int. J. Metrol. Qual. Eng. 9, 14 (2018) 